\title{
Article choice, theory of mind, and memory in children with high-functioning autism and children with specific language impairment
}

\author{
University of Amsterdam \\ AVA CREEMERS \\ University of Pennsylvania
}

JEANNETTE SCHAEFFER and MEREL VAN WITTELOOSTUIJN

Received: March 16, 2016 Accepted for publication: September 4, 2017

\author{
ADDRESS FOR CORRESPONDENCE \\ Jeannette Schaeffer, Department of Cultural Analysis \& Linguistics, University of Amsterdam, \\ Spuistraat 134, 1012 VB Amsterdam, The Netherlands. E-mail: j.c.schaeffer@uva.nl
}

\begin{abstract}
Previous studies show that young, typically developing (TD) children (<age 5) and children with specific language impairment (SLI; >age 5) make errors in the choice between a definite and an indefinite article. Suggested explanations for overgeneration of the definite article include failure to distinguish speaker from hearer assumptions, and for overgeneration of the indefinite article failure to draw scalar implicatures, and weak working memory. However, no direct empirical evidence for these accounts is available. In this study, 27 Dutch-speaking children with high-functioning autism, 27 children with SLI, and 27 TD children aged 5-14 were administered a pragmatic article choice test, a nonverbal theory of mind test, and three types of memory tests (phonological memory, verbal, and nonverbal working memory). The results show that the children with high-functioning autism and SLI (a) make similar errors, that is, they overgenerate the indefinite article; (b) are TD-like at theory of mind, but (c) perform significantly more poorly than the TD children on phonological memory and verbal working memory. We propose that weak memory skills prevent the integration of the definiteness scale with the preceding discourse, resulting in the failure to consistently draw the relevant scalar implicature. This in turn yields the occasional erroneous choice of the indefinite article $a$ in definite contexts.
\end{abstract}

Keywords: article choice; high-functioning autism; phonological and working memory; specific language impairment; theory of mind

Cross-linguistic research on the acquisition of article choice shows that young monolingual typically developing (TD) children acquiring a two-article language system based on definiteness often use definite articles where adults would use an indefinite (Karmiloff-Smith, 1979; Maratsos, 1976; Schaeffer \& Matthewson, 
Schaeffer et al.: Article choice in children with HFA and with SLI

2005; van Hout, Harrigan, \& de Villiers, 2010; Zehler \& Brewer, 1982). This is illustrated in (1):

(1) Child: I dreamed about the giraffe last night.

(Adult: What giraffe?)

This has been attributed to the failure to consider the hearer's knowledge state as independent of the speaker's, or to take the hearer's perspective, which in turn may be related to an immature theory of mind (ToM).

Moreover, non-adultlike interpretation of the indefinite article $a$ is also found in TD English-speaking children (van Hout et al., 2010), as exemplified in (2), which was presented with a picture of a teacher with a piece of cake, and several other pieces of cake on a table.

(2) Experimenter: "John sees his teacher with a piece of cake.

He asks her if he can have a piece of cake."

Target: a different piece (van Hout et al., 2010, p. 1985).

Van Hout et al.'s (2010) results show that in such a situation, children often choose the teacher's piece of cake. The overly liberal interpretation of the indefinite article (i.e., choosing the already mentioned referent for the indefinite) has been explained by the failure to draw so-called scalar implicatures, implicitly communicated inferences that go beyond the explicit meaning of an utterance, and that are therefore pragmatic in nature. Non-adultlike use of indefinites has also been found in production (English child language: Schafer \& de Villiers, 2000; Dutch child language: Keydeniers, Eliazer, \& Schaeffer, 2017), as illustrated in (3):

(3) Experimenter: Hey, who do you see in the picture? Child: Katrijn.

Experimenter: What else do you see? Child: A train!

Experimenter: And what did Katrijn just do?

Child: She pushed a train. (Schaeffer \& Matthewson, 2005, replicated in Keydeniers et al., 2017. Translated from Dutch.)

Keydeniers et al. (2017) propose that, as in interpretation, children's substituting the definite article with an indefinite one may also be due to the underdeveloped pragmatic skill of drawing scalar implicatures.

Besides studies in typical language development, there are a few investigations of article choice in children with specific language impairment (SLI). One study shows no impairment of article choice in the spontaneous speech of 4-year-old English-acquiring children with SLI (Schaeffer, Hacohen, \& Bernstein, 2003). The other two (experimental) studies report that English-speaking children with SLI older than 5 overgenerate indefinite articles in definite contexts (Chondrogianni \& Marinis, 2015; Polite, Leonard, \& Roberts, 2011). Polite et al. (2011) propose that this may be attributed to weak verbal working memory in children with SLI. However, as Polite et al. did not conduct independent working memory tests, this is merely a suggestion. Chondrogianni and Marinis (2015) propose that overgeneration of the indefinite article by children with SLI results from problems with the anaphoric use of definite articles, that is, with maintaining discourse 
continuity via linguistic means. As they do not go into detail, it is not entirely clear what this means, and what this may follow from.

In summary, non-adultlike or atypical article choice has been suggested to be due to immature ToM, immature pragmatics, and weak verbal working memory, although convincing independent evidence for these underlying reasons has not yet been presented. The current study therefore further investigates the potential associations of atypical article choice with underdeveloped ToM, pragmatics, and/or (working) memory in two clinical child populations: one that is known to have weak ToM and pragmatics, namely, children with high-functioning autism (HFA), and one known to suffer from weak (working) memory (besides impaired morphosyntax), namely, SLI. ${ }^{1}$

In the next section, we provide some more relevant details on children with HFA and children with SLI. In addition, we describe and discuss the theoretical framework and previous acquisition studies on pragmatic article choice, ToM, and different types of memory.

\section{BACKGROUND}

\section{HFA and SLI}

Typical characteristics of children with HFA (a subgroup of children with autism spectrum disorders; ASD) include normal intelligence, fluent speech, but significantly impaired communication and deviant pragmatics (see Baron-Cohen, 1988; Eigsti, de Marchena, Schuh, \& Kelley, 2011; Frith, 1989; Tager-Flusberg, 1989, for reviews). Some children with HFA have also been reported to have additional grammatical impairments (Perovic, Modyanova, \& Wexler, 2013a, 2013b), but this is not considered their primary impairment. As for their nonlinguistic cognitive abilities, children with HFA often have an impaired ToM (Baron-Cohen, 1988; Colle, Baron-Cohen, \& Hill, 2007; Durrleman et al., 2016; Sperber \& Wilson, 2002, but cf. Schaeffer, 2016). The results of studies investigating verbal working memory in ASD, including HFA, are inconsistent. Some studies find evidence of working memory deficits (Joseph, Steele, Meyer, \& Tager-Flusberg, 2005; Schuh \& Eigsti, 2012), whereas others report normal performance (Griffith, Pennington, Wehner, \& Rogers, 1999; Koshino et al., 2005; Ozonoff \& Strayer, 2001; Russell, Jarrold, \& Henry, 1996; Schaeffer, 2016), or mixed performance (e.g., Bennetto, Pennington, \& Rogers, 1996). Similarly, the investigation of nonverbal (visuospatial) working memory in individuals with ASD, including HFA, renders mixed results as well (Benetto et al., 1996; Luna et al., 2002). There is thus no consensus regarding working memory skills of children with HFA.

In contrast, although all children with SLI show grammatical impairments, many children with SLI have intact pragmatics (Friedmann \& Novogrodsky, 2008; 2011; van der Lely, 1998). Nevertheless, additional pragmatic impairments are sometimes found in SLI (Bishop, 2000; Bishop, Chan, Adams, Hartley, \& Weir, 2000; Botting \& Conti-Ramsden, 2003).

Furthermore, children with SLI are often reported to have impaired verbal working memory (e.g., Montgomery, 2003; Vugs, Cuperus, Hendriks, \& Verhoeven, 2013; Weismer, Evans, \& Hesketh, 1999), and they typically score low on 
phonological memory tasks such as nonword repetition (NWR; e.g., Archibald \& Gathercole, 2006; Bishop, North, \& Donlan, 1996; Dollaghan \& Campbell, 1998; Gathercole \& Baddeley, 1990; Girbau \& Schwartz, 2007; Rispens \& Baker, 2012; Weismer et al., 2000). Working memory deficits in SLI have also been shown in the nonverbal domain (Henry, Messer, \& Nash, 2012; Schaeffer, 2016; Vugs et al., 2013).

As article choice errors have been associated with immature ToM, immature pragmatics, and weak working memory, the question arises as to what extent children with HFA (with, supposedly, weak ToM and pragmatics) and children with SLI (with, supposedly, weak memory) who are beyond the typical age of article choice acquisition (>age 5) experience problems in article choice. In order to understand possible article choice errors, the adult facts and the theoretical framework of article choice are presented in the next section.

\section{Article choice in adult language}

In the literature, definite noun phrases are characterized by "uniqueness," and by "familiarity." Uniqueness theories focus on the semantic requirement that the referent of the definite noun phrase be uniquely identifiable to the addressee (Hawkins, 1991; Russell, 1905). Familiarity theories emphasize the pragmatic requirement that the referent be familiar to speaker and hearer. Both theories encounter some empirical problems (for an overview, see Abbott, 1999, 2003), but it goes beyond the scope of this paper to discuss these. In this study, we focus on the pragmatic requirement of familiarity for definites, because it is this part of pragmatics that is considered to be associated to ToM, which in turn appears to be impaired in children with HFA, but usually not in children with SLI.

Beliefs that are shared by all interlocutors in a discourse are said to be in the socalled common ground of the discourse (see Heim, 1982; Stalnaker, 1974, 1978). As argued by Heim (1982), the definite article the places a requirement on the content of the common ground at the time of utterance. Speaking informally, the use of [the $\mathrm{N}$ ] requires that the existence of a (unique) referent corresponding to that nominal phrase be part of the shared assumptions between speaker and hearer at the time of utterance. If the existence of such a referent is not part of the shared assumptions between speaker and hearer, infelicity results, as illustrated in (4):

(4) a. Ik heb gisteravond over de giraffe gedroomd!

"I dreamed about the giraffe last night!"

b. Welke giraffe?

"What giraffe?"

One way to become part of the common ground is illustrated in (5):

(5) Dit is een verhaal over een giraffe.

"This is a story about a giraffe."

De giraffe woonde in een land genaamd Tanzania.

"The giraffe lived in a country called Tanzania."

The existence of a unique entity corresponding to the definite noun phrase de giraffe is part of the shared assumptions between speaker and hearer, that is, the 
Schaeffer et al.: Article choice in children with HFA and with SLI

Table 1. The Dutch adult article system

\begin{tabular}{ccccc}
\hline \hline Context & Assumed by & Label & Common Ground & Dutch Article \\
\hline A & $\begin{array}{c}\text { Speaker and } \\
\text { hearer } \\
\text { B }\end{array}$ & Definite-referential & $\begin{array}{c}\text { Part of common } \\
\text { ground } \\
\text { Not part of } \\
\text { common ground }\end{array}$ & De \\
C & $\begin{array}{c}\text { Neither speaker } \\
\text { nor hearer }\end{array}$ & Indefinite-nonreferential & $\begin{array}{c}\text { Not part of } \\
\text { common ground }\end{array}$ & Een \\
\hline \hline
\end{tabular}

common ground, because it was established in the previous discourse, namely, by the indefinite noun phrase een giraffe.

Sometimes, the speaker but not the hearer assumes the existence of an entity corresponding to the noun phrase. For example, in the first sentence in (3), the speaker has grounds for an existential assertion about giraffes, while the hearer does not. This type of indefinite is usually referred to as specific or referential. As we can see in (6), it is also possible for neither the speaker nor the hearer to have grounds for an existential assertion:

(6) Ik heb zin om een boek te lezen.

"I feel like reading a (any) book."

In (6), neither the speaker nor the hearer necessarily has grounds for an existential assertion regarding "book." This use of an indefinite is referred to as nonspecific or nonreferential.

Inspired by Schaeffer and Matthewson (2005), we propose the schema in Table 1 for the canonical realizations of the three possible assumption states in the Dutch adult article system ("Assumed by X" is shorthand for "X has grounds for an existential assertion").

In the remainder of the text, A-contexts are referred to as "definite referential" contexts, B-contexts as "indefinite referential," and C-contexts as "indefinite nonreferential."

\section{Previous studies on article choice in TD children}

As mentioned above, cross-linguistic research on the typical acquisition of article choice shows that young children acquiring a two-article language system based on definiteness often overgenerate definite articles in indefinite contexts (KarmiloffSmith, 1979; Maratsos, 1976; Schaeffer \& Matthewson, 2005; van Hout et al., 2010; Zehler \& Brewer, 1982). Schaeffer and Matthewson (2005) show that in an elicited production task 26 English-acquiring children aged 2 years, 1 month (2;1)-3;10 overgenerate the definite article in indefinite referential contexts (Bcontexts) $25 \%$ of the time. The authors explain this phenomenon by the lack of a pragmatic concept, as formulated in (7):

(7) Concept-of-non-shared-assumptions (CNSA)

Speaker and hearer assumptions are always independent. 
If the CNSA is absent, speaker and hearer assumptions are not always independent, implying that there are situations in which the speaker automatically attributes her/his own assumptions to the hearer. The CNSA expresses an obligation for the speaker to consider the hearer's assumptions as a separate entity and therefore as something that is in principle different from the speaker's assumptions. However, in certain cases, speaker and hearer assumptions may coincide.

One of the effects of lacking the CNSA concerns the distinction of articles. As illustrated in the schema in Table 1, in adult English (or Dutch, for that matter), the semantics of articles mandates the grouping together of contexts $\mathrm{B}$ and $\mathrm{C}$ (as opposed to A). If a speaker attributes her own (speaker) beliefs to the hearer, she will not distinguish environment B (believed by speaker only) from environment A (believed by speaker and hearer). In other words, environment B becomes environment A. In these cases, the speaker will use the article appropriate for environment A, which is the in English, or de in Dutch. Thus, in the cases in which the speaker does not distinguish speaker and hearer beliefs, she groups together environment $\mathrm{A}$ and $\mathrm{B}$, as opposed to $\mathrm{C}$. Thus, the lack of the CNSA sometimes yields a oneto-one mapping between speaker beliefs and the form of the article (rather than between common ground and the form of the article). If the referent is assumed to exist by the speaker, the is used; if no referent is assumed to exist by the speaker, $a$ is used. Once the CNSA is acquired (around the age of 3 or 4), contexts A and $\mathrm{B}$ are distinguished, and the overgeneration of the definite article disappears. Research on the acquisition of sentential subjects provides further evidence for the hypothesis that TD children initially lack the CNSA (Gordishevsky \& Avrutin, 2004; Westergaard, 2008).

The description of the CNSA may remind the reader of ToM (Premack \& Woodruff, 1978). Although Schaeffer and Matthewson (2005) are hesitant to fully equate the CNSA to ToM, they do acknowledge that the two are probably related, and suggest that the CNSA may be a component or a precursor of ToM.

On the comprehension side of articles, van Hout et al. (2010) found nonadultlike interpretation of the indefinite article $a$. Comprehension of the indefinite article was tested with a so-called referent-selection paradigm. Children aged 3;7$5 ; 3(M=4 ; 6)$ were presented with pictures and a story and asked to move an item in the picture to match the story. An example of an item testing the comprehension of indefinite article was presented in (2), here repeated as (8).

(8) Experimenter: "John sees his teacher with a piece of cake.

He asks her if he can have a piece of cake."

Target: a different piece (van Hout et al., 2010, p. 1985).

The results indicate that children incorrectly interpret $a$ as referring to the unique referent (the piece of cake held by the teacher) $59 \%$ of the time.

Van Hout et al. (2010) explain this non-adultlike interpretation of indefinites by the failure to draw scalar implicatures, as it has frequently been shown that children have difficulties with scalar implicatures (see Pouscoulous, Noveck, Politzer, \& Bastide, 2007). Scalar implicatures are implicitly communicated propositions linked to relatively weak terms. The general consensus is that the weaker term (e.g., the indefinite article $a$ ), while logically/semantically compatible with a stronger 
term from the same scale (e.g., the), prompts the inference because the speaker did not use the stronger term (Carston, 1998; Chierchia, 2004; Hawkins, 1991; Horn, 1989, 2006; Levinson, 2000; Wilson \& Sperber, 2004). This follows from Grice's (1975) maxim of quantity that requires the speaker to give as much information as needed, but no more. A scalar implicature thus is an inference that goes beyond the explicit meaning of an utterance, and is due to pragmatic factors.

Hawkins (1991) and Horn (2006) propose that adults draw a scalar implicature when they interpret indefinite noun phrases. They argue that the and $a$ provide a contrastive set, in which the is the logically stronger and most informative member of the pair: $<a$, the $>$. Indefinite interpretations are then analyzed as implicatures that result from not using the definite article in corresponding expressions (Hawkins, 1991, p. 417). Consequently, it follows that the indefinite article may be interpreted in two different ways: either with an inference-driven, pragmatic reading that excludes the definite reading, or with just its literal, logical/semantic meaning (i.e., the existence of a referent), which is also compatible with the: the truth value of a sentence does not change depending on the use of a definite or an indefinite article. To obtain the inference-driven pragmatic reading, the calculation of a scalar implicature is required: the use of the weak indefinite article implies that the stronger definite reading does not hold. Adults always draw a scalar implicature upon hearing an indefinite article, whereas children do not. If children fail to draw a scalar implicature when they interpret indefinite noun phrases, as in van Hout et al.'s (2010) comprehension study, they arbitrarily choose between a determined referent meaning and a nondetermined referent meaning when they hear an indefinite.

Errors regarding the indefinite article have also been found in the production of TD children. Schafer and de Villiers (2000) report the results of an elicitation task (without visual support) showing that English-speaking TD children aged 3;6-5;5 inappropriately produce the indefinite article in contexts requiring a definite article. Schafer and de Villiers explain the results by suggesting that the children do not make scalar inferences yet, because they lack ToM. The authors argue that the assessment of other people's belief perspectives is necessary for the calculation of a scalar inference (p. 617). Keydeniers et al. (2017) show that Dutch-speaking TD 2-year-olds overgenerate definite articles in indefinite contexts and overgenerate indefinite articles in definite contexts. They also suggest that these production errors regarding the indefinite articles can be explained by the failure to consistently draw the scalar implicature related to definiteness.

\section{Previous studies on article choice in children with SLI and in children with HFA}

The first study on article choice in SLI was by Schaeffer et al. (2003), who conducted a spontaneous speech study on article omission and overgeneration of the in a group of 14 English-speaking children with SLI aged 3;11-4;10 and their ageand mean length of utterance-matched TD controls. None of the children with SLI (or their TD controls, for that matter) overgenerated the definite article the in indefinite contexts. However, as the transcripts used for this study do not provide all the necessary pragmatic information, a controlled, experimental study was called for. 
An elicited production task on article choice was carried out by Chondrogianni and Marinis (2015), who investigated a group of 24 English-speaking children with SLI $(M$ age $=7 ; 5)$. Although no difference with the TD age-matched controls was found on the indefinite referential condition, the English-speaking children with SLI perform significantly worse than their TD age-matched controls on two types of definite conditions, namely, an anaphoric and a bridging condition. Most of the errors were substitutions of the indefinite article $a$ for the definite article the. Further analysis shows that $25 \%$ of the children with SLI in Chondrogianni and Marinis's study overuse the indefinite article at substantial rates (i.e., more than $50 \%$ of the time). This vulnerability of the definite article was also found by Polite et al. (2011) for English-acquiring children (aged 4;5-7;0) with SLI and TD- and mean length of utterance-matched (aged 2;10-3;9) groups, who inappropriately used the indefinite article in contexts requiring a definite article.

Following De Cat (2011) and Krämer (2003), Chondrogianni and Marinis (2015) explain the overgeneration of the indefinite article in young TD children and children with SLI by proposing that they are primarily challenged by the discourserelated properties of the anaphoric use of definite articles, or, in other words, with maintaining discourse continuity via linguistic means. As this is a rather broad explanation that has not been investigated independently in the same children, the validity of this proposal should be determined (and refined) by future studies that independently investigate the maintenance of discourse continuity via linguistic means. This could be accomplished by, for example, studying other linguistic elements that require an antecedent, such as pronouns. In an alternative attempt to explain overgeneration of the indefinite article, Polite et al. (2011) argue that retaining the previously introduced discourse antecedent, which is necessary in uttering a definite article, constitutes an additional demand on verbal working memory for children with SLI. As children with SLI are often reported to have weak verbal working memory, this account seems more convincing. However, Polite et al. (2011) did not administer working memory tests with the same groups of children, and thus independent evidence for this hypothesis remains absent so far.

As for HFA, Schaeffer (2016) explores the question as to what extent children with SLI and children with HFA differ from each other and resemble each other in terms of grammar, pragmatics, and extralinguistic cognition, and includes an article choice test in her large test battery. She reports that both the children with SLI and the children with HFA overgenerate indefinite articles in definite contexts, but neither elaborates on this result, nor provides an explanation. The current study zooms in on this error, using the same data set, and adding verbal working memory and phonological memory results to the equation.

In a nutshell, previous acquisition studies on article choice in young TD children suggest that (a) overgeneration of the definite article in indefinite referential contexts is due to the failure to consistently separate speaker from hearer assumptions, which is possibly related to an immature ToM; and (b) overly liberal interpretation/overgeneration of the indefinite article results from the pragmatic failure to calculate the scalar implicature related to definiteness. As for SLI, weak working memory has been proposed to be responsible for overgeneration of the indefinite article in definite contexts by children with SLI older than 5 . 
Schaeffer et al.: Article choice in children with HFA and with SLI

In the following sections we discuss ToM and (working) memory in individuals with SLI and individuals with HFA.

\section{ToM}

ToM is the cognitive ability that allows individuals to attribute mental states to oneself and others (Premack \& Woodruff, 1978). The component of ToM we focus on in this study is false belief, that is, the ability to represent the absence of knowledge in another person. False belief tasks (Wimmer \& Perner, 1983) show that TD children go through a rapid development between the ages of 3 and 4: while 3-year-olds typically fail to recognize their own and other's false beliefs, 4-year-olds do well on false belief tasks (e.g., Wellman, Cross, \& Watson, 2001). Since children with ASD (including children with HFA) have been reported to have a consistent deficit on different versions of false belief tasks, it has been argued that ToM deficits underlie the attested deficits in social communication and pragmatic language of individuals with autism (e.g., Levy, 2007; Sperber \& Wilson, 2002).

However, Colle et al. (2007) point out that standard ToM assessments rely heavily on language, and that these measures therefore cannot be used for nonverbal children with autism or children with SLI. A nonverbal version of the false belief task was constructed by Call and Tomasello (1999), in which the verbal component is reduced to a minimum. This task is used by Colle et al. (2007) to investigate ToM in nonverbal (i.e., low-functioning) children with ASD and, important for the present study, children with SLI. Colle et al.'s results show that a ToM impairment is still evident in low-functioning children with autism $(n=12, M$ age $=8.1)$. Furthermore, the nonverbal false belief test did not present any difficulty for the TD children ( $n=15, M$ age 4.6) and the children with SLI ( $n=15, M$ age 8.3). Colle et al.'s results are consistent with the majority of earlier studies (e.g., Miller, 2001) showing that children with SLI have normal abilities in ToM when the linguistic demands of the task are minimized. In contrast, Schaeffer (2016) reports TD-like performance on Colle et al.'s ToM task for both the SLI and the HFA groups.

\section{Working memory}

Working memory is defined as a limited capacity system by which information is temporarily maintained and stored in an activated, online state during the performance of cognitive tasks (Baddeley, 1986, 2003). Current views of working memory involve a three-component model of a central executive (the attentional control system) and two storage systems: the visuospatial sketchpad and the phonological loop (based on the model first proposed by Baddeley \& Hitch, 1974). The visuospatial sketchpad is concerned with constructing and manipulating visual imagery. Its verbal equivalent, the phonological loop, is specialized for the temporary storage of phonological material (phonological memory). In this sense, both verbal and nonverbal working memory include the central executive, while verbal working memory manipulates information from phonological (short-term) memory, and nonverbal working memory information from visuospatial (short-term) memory. 
This study investigates phonological memory (also referred to as phonological short-term memory), verbal working memory, and nonverbal working memory. Phonological memory refers to the ability to store verbal information in shortterm memory, that is, into the phonological loop. Phonological memory is typically measured through NWR (e.g., Gathercole, 2006; Gathercole, Willis, Baddeley, \& Emslie, 1994) and digit span forward tasks (e.g., Vugs et al., 2013). Both tasks do not require the subjects to manipulate or update the phonological information, but merely to store it.

In contrast, verbal working memory refers to the ability to process verbal information while it is being stored. Verbal working memory tasks thus not only require phonological storage (as the phonological loop tasks do) but also tap into central executive processes that are responsible for maintaining information active and updating the information that is stored (Verhagen \& Leseman, 2016). Verbal working memory is typically measured through complex span tasks that require the simultaneous short-term storage and processing of information, such as the digit span backward task.

Finally, nonverbal working memory refers to nonverbal central executive tasks. Nonverbal working memory tasks minimize or remove the phonological coding component that is present in verbal working memory tasks, and instead tap into the visuospatial working memory. Similar to verbal working memory tasks, nonverbal working memory tasks tap into central executive processes. A commonly used measure of executive-loaded visuospatial working memory is the odd-one-out span task (Henry, 2001). For a description of some of these memory tasks, see the Method section.

\section{RESEARCH QUESTIONS}

Based on findings of previous studies on article choice, ToM, and working memory, we formulate the following research questions:

1. Do children with HFA and children with SLI older than 5 have problems with article choice?

2. If so, are these problems related to (a) false belief, (b) phonological memory, (c) verbal working memory, or (d) nonverbal working memory?

\section{METHOD}

\section{Participants}

To answer our research questions, the same children as in Schaeffer (2016) were investigated: a total of 81 Dutch-speaking children, divided over three groups: 27 children with HFA (aged 5-14, $M=10 ; 1, S D=2 ; 3$ ), 27 children with SLI (aged $6-14, M=9 ; 8, S D=2 ; 2$ ), and a control group of 27 TD children (aged 6-14, $M$ $=10 ; 0, S D=2 ; 1)$. See Table 2 for an overview of the children's characteristics. The participants of the three groups were individually matched on age and gender. Children with SLI had all previously received a diagnosis by a certified speechlanguage pathologist and were enrolled in special schools for children with speech 


\begin{tabular}{|c|c|c|c|c|c|c|}
\hline & \multicolumn{2}{|c|}{$\begin{array}{c}\text { Age } \\
\text { (years;months) }\end{array}$} & \multicolumn{2}{|c|}{$\begin{array}{l}\text { Expressive } \\
\text { and Receptive } \\
\text { Language } \\
\text { (CELF) }\end{array}$} & \multicolumn{2}{|c|}{$\begin{array}{c}\text { Social } \\
\text { Interaction } \\
\text { Difference } \\
\text { Score } \\
\text { (SIDI CCC) }\end{array}$} \\
\hline & $M$ & $S D$ & $M$ & $S D$ & $M$ & $S D$ \\
\hline TD & $9 ; 10$ & $2 ; 2$ & 73.4 & 24.9 & - & - \\
\hline SLI & $9 ; 7$ & $2 ; 2$ & 7.6 & 7.3 & 16 & 13.5 \\
\hline HFA & $10 ; 0$ & $2 ; 3$ & 53.7 & 29.5 & 82 & 20 \\
\hline
\end{tabular}

Note: TD, typically developing; SLI, specific language impairment; HFA, highfunctioning autism; CELF, Clinical Evaluation of Language Fundamentals; SIDI CCC, Social Interaction Difference Index Children's Communication Checklist.

and language problems in the Netherlands. Children with HFA were contacted through Dutch organizations for autism, autism groups on Facebook, and personal contacts and were reported by psychiatrists to have an official diagnosis on the autism spectrum. All children had an IQ $>85$, had not been officially diagnosed with any additional disorder, were monolingual speakers of Dutch, and had normal hearing. These inclusion and exclusion criteria were confirmed in teacher and/or parent reports.

To corroborate the SLI and HFA diagnoses, information from several background measures was gathered. First, age-normalized scores of expressive and receptive linguistic ability were obtained with the Clinical Evaluation of Language Fundamentals (CELF-4-NL; Kort, Schittekatte, \& Compaan, 2008). Whereas the SLI group performed far below the norm score of the 50th percentile $(M=7.9, S D$ $=7.34$ ), the HFA and TD groups performed around or above the norm score (HFA: $M=53.7, S D=29.5$; TD: $M=73.4, S D=24.9$ ), demonstrating that they are not language impaired. Second, after testing, the parents of all the children with HFA and with SLI were asked to fill out the Dutch version of the Children's Communication Checklist (CCC-2-NL; Geurts, 2007). The CCC is a parents' questionnaire that provides an impression of the child's pragmatic and grammatical difficulties. Subtracting the sum of scores on the "language areas" (speech, syntax, semantics, and coherence) from the sum of scores on "pragmatic areas" (initiation, nonverbal communication, social relations, and interests) derives the Social Interaction Difference Index (SIDI). This is a difference score that is given as a percentile. Children who score beneath the 10th percentile have more structural language problems than pragmatic difficulties, whereas the opposite is true for children scoring above the 90th percentile. Parents of 26 HFA and of 13 SLI participants completed and returned the CCC. Because a personal relationship was built with parents of children with autism, due to testing in their home, response rates were higher in the HFA group than in the group of children with SLI. As expected, the HFA group has a high SIDI score $(M=82, S D=20)$, whereas the SLI group has a low SIDI score $(M=16, S D=13.5$, although note that these are the results of a 
subset of the children with SLI). This shows that the HFA group experiences more pragmatic difficulties, underscoring their autism diagnosis, while the SLI group has more structural language problems, confirming their SLI diagnosis.

\section{Materials and procedure}

ToM. The nonverbal ToM task used in the present study was adopted from Colle et al. (2007). In this task, two experimenters are present and participants complete a pretest, screening, and the actual test phase, consisting of three false belief items and three control items. In the false belief items, a screen is placed between the participant and one of the experimenters (Exp. 1), while the other experimenter (Exp. 2) can see both sides of the screen. Exp. 1 hides an eraser in one of two identical containers in such a way that Exp. 2 can see it, but the participant cannot. While Exp. 2 leaves the scene, Exp. 1 removes the screen so that the participant can see, and then switches the positions of the two containers. When Exp. 2 returns to the scene and is asked "Where is the eraser?" he/she responds by pointing at the incorrect container (pretending not to know about the switch). Finally, the participant is asked to point to the container that holds the eraser (i.e., choose the container that was not indicated by Exp. 2). The three control items resemble the false belief items, except that there was no screen present and the two containers were not switched. The six test-phase items were presented in the same randomized order to all participants. Scores reported are the average numbers of correct responses on the three false belief items; that is, the maximum score was 3 .

Phonological memory: Nonword repetition and digit span forward. Phonological memory was assessed through an NWR task (Rispens \& Baker, 2012) and the forward condition of the digit span task (Wechsler Intelligence Scale for ChildrenRevised; Wechsler, 1974). In Rispens and Baker's NWR task, the participant is asked to repeat 40 nonsense words, varying in syllable length (two to five syllables) and phonotactic probability (either high or low according to Dutch phonotactics). Thus, items range from items with two syllables with high phonotactic probability (e.g., kuimup) to items with five syllables with low phonotactic probability (e.g., geumuwoekuubir). Items are scored as either correct or incorrect and scores on the NWR are presented as the percentage of items correctly repeated (out of 40).

In Wechsler's digit span forward task, the participant is asked to repeat sequences of digits of increasing length, in the same order. Thus, when the experimenter says "3-8-6-2," the participant has to repeat "3-8-6-2." Numbers are read at a pace of approximately $1 \mathrm{~s}$ per digit. The task is preceded by three practice items that contain 2-3 digits. Following practice, the participant starts at three digits and works her way to a maximum of eight digits. Each number of digits is tested in two items and the cutoff point is when a participant responds incorrectly to both items of a certain level. Scores reported in the present study are the average maximum number of digits repeated correctly.

Verbal working memory: Digit span backward. The backward condition of the digit span (Wechsler Intelligence Scale for Children-Revised; Wechsler, 1974) is 
administered in a similar manner to the forward condition and differs in only one respect: the participant is asked to repeat the digits in reverse order (e.g., in the example above, the child would have to reply "2-6-8-3"). Again, scores reported here represent the maximum number of digits repeated correctly.

Nonverbal working memory: Odd-one-out. Nonverbal working memory was assessed through a digital version of the so-called odd-one-out task (based on Henry, 2001), developed by Janssen (2016). This task requires the participant to single out the odd-one-out among three geometrical figures and remember their spatial locations over trials. This task increases in complexity, to a maximum of six trials, with each phase consisting of four items. The measure that is adopted in the present study is the participants' memory level, which is calculated as the maximum number of trials over which each participant can remember the spatial locations of the odd-one-out (maximum score of 6).

Article choice. Our article choice materials consist of an elicited production task in which the participant is sitting next to an experimenter (Exp. 1) and watches pictures and short video clips on a computer screen. Participants are asked to describe each scene to a second experimenter (Exp. 2) who cannot see the screen. Following Schaeffer and Matthewson's (2005) schema on definiteness and referentiality, three conditions are distinguished: (a) definite $(N=6)$; (b) indefinite-referential $(N=6)$; and (c) indefinite-nonreferential $(N=6)$. In the definite condition, participants are asked to describe an action after having introduced both the subject and the object (e.g., She rolled the ball), whereas the indefinite conditions requires the description of an object that has not yet been introduced (e.g., She drew a heart / He is going to draw a tree). A sample condition of the definite condition is given in (9).

(9) Sample scenario Definite condition

Situation: Picture of a puppet with a ball (visible to participant, but not to experimenter).

Exp: Hey, who do you see in the picture?

Participant: *Name*! (Name of the puppet)

Exp: What else do you see?

Participant: A ball!

Situation: Movie of puppet rolling the ball.

Exp: What did *name* just do?

Target: She rolled the ball.

Sample scenarios of the other conditions are provided in Appendix A. The article choice experiment includes 18 fillers, eliciting utterances with a scrambled or a nonscrambled direct object (which were later used for a different study). The 36 test items were administered in the same randomized order to all participants. Scores presented in the results section reflect the percentage of accurate answers (i.e., correct article choice), percentage of substitutions by the other article, and irrelevant answers (e.g., demonstratives and article omission). 


\section{General procedure}

The tasks reported here are part of a larger test battery that was administered to children with HFA, SLI, and TD as part of a project in collaboration with Iris Duinmeijer, University of Amsterdam. Participants with SLI and TD were individually tested in a quiet room at their school, while children with HFA were tested in their home. Testing took place over three sessions that lasted approximately $60 \mathrm{~min}$. The CELF-4-NL and digit span tasks were administered during the first session, the NWR in the second session, and the odd-one-out, article choice, and ToM tasks took place in the third session. The same, fixed, order was used for all children both within tasks and between tasks (article choice, odd-one-out, ToM). This order was randomized in the ToM and article choice tasks.

\section{Statistical analysis}

Results were analyzed using Kruskal-Wallis tests. This is the nonparametric equivalent of a (one-way) analysis of variance test. Follow-up analyses were performed using Mann-Whitney $U$ tests, which are nonparametric $t$ tests. Correlations between the different tasks were Spearman rank correlation orders. The rationale behind this choice is the nonnormality of the data. The results on the ToM task were compared to chance level (50\%) by using one-sample $t$ tests.

\section{Hypotheses and predictions}

If, as the literature suggests, children with HFA have underdeveloped ToM, in particular, underdeveloped false belief skills, we predict that our HFA group scores significantly lower than the TD group on the false belief items of the ToM task, and that they overgenerate definite articles in the indefinite referential condition of the article choice test. Moreover, we predict a correlation between false belief scores and scores on the indefinite referential condition of the article choice test. Furthermore, hypothesizing that children with HFA have pragmatic deficits, we predict that in the definite condition, failure to calculate the scalar implicature results in overgeneration of the indefinite article in the definite condition of the article choice test. Since previous literature on phonological and working memory reports mixed results for individuals with HFA, we do not make any particular predictions regarding this, but stick to our research question as to whether children with HFA suffer from phonological and/or working memory problems or not.

As for SLI, following previous studies, we hypothesize that they are not primarily impaired in ToM/false belief or pragmatics, but that they have weak phonological and working memory. We therefore predict that the children with SLI score TD-like on the false belief items of the ToM test, and on the indefinite referential condition of the article choice test. In contrast, we predict that they score significantly lower than the TD children on all memory tests. If this prediction is borne out, and following Polite et al.'s (2011) hypothesis that overgeneration of indefinite articles in children with SLI is caused by weak working memory, we predict that the children with SLI overgenerate indefinite articles in the definite condition of 


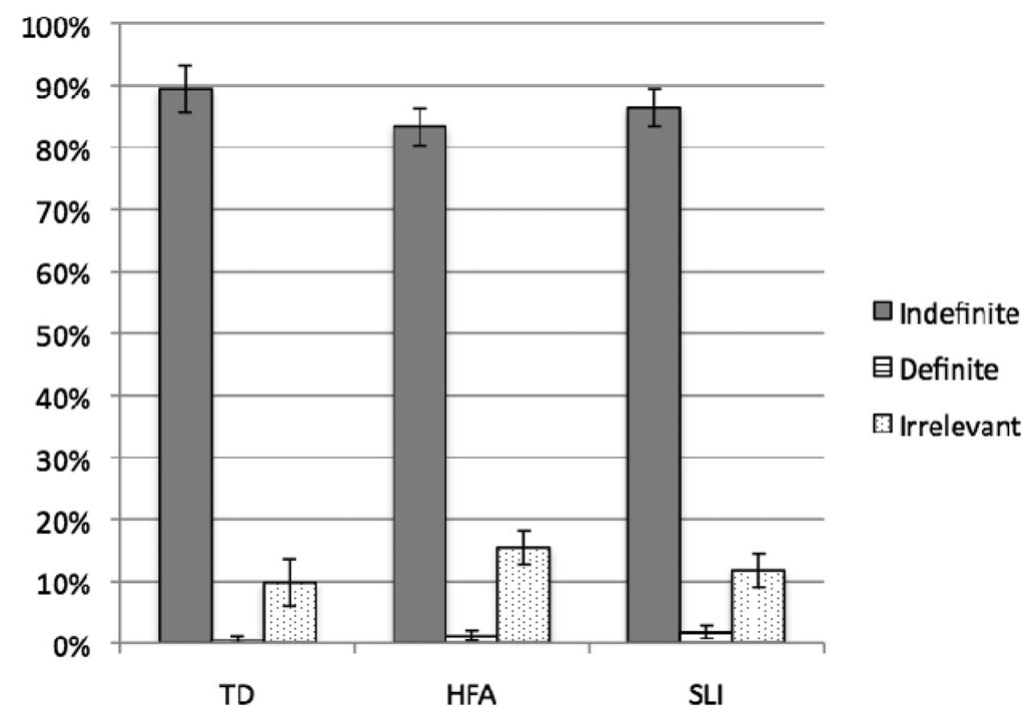

Figure 1. Indefinite nonreferential condition proportions of indefinite (correct), definite (incorrect), and irrelevant responses.

the article choice test. Moreover, we predict a correlation between scores on the memory tests and scores on the definite condition of the article choice test.

\section{RESULTS}

\section{Article choice}

In this section, we present the results on article choice as also reported by Schaeffer (2016). The results on the indefinite nonreferential condition and the indefinite referential condition of the article choice experiment are given in Figures 1 and 2 , respectively. The tall bars in Figures 1 and 2 show that all children overwhelmingly choose to produce the target indefinite article in both indefinite conditions. In the indefinite nonreferential condition (Figure 1), the TD children correctly produce indefinite articles at a rate of $89.5 \%(S D=19.7 \%)$, the HFA group $83.3 \%$ $(S D=15.3 \%)$, and the SLI group $86.4 \%(S D=16.0 \%)$ of the time. Furthermore, irrelevant responses are given by all child groups (TD: $9.9 \%, S D=19.8 \%$; HFA: $15.4 \%, S D=14.6 \%$; SLI: $11.7 \%, S D=14.5 \%$ ). The SLI group produces a negligible number of definite responses $(1.9 \%, S D=5.3 \%)$ in this condition. Kruskal-Wallis tests reveal no significant differences between the groups for any of the response types: referential indefinites, $\chi^{2}(2)=4.507, p=.105$; definites, $\chi^{2}(2)=1.067, p=.587$; and irrelevant, $\chi^{2}(2)=4.925, p=.085$. As for the indefinite referential condition, Figure 2 shows even higher proportions of correct indefinite responses (TD: $98.6 \%, S D=4.9 \%$; HFA: $96.3 \%, S D=7.1 \%$; SLI: $97.5 \%, S D=7.6 \%$ ). Irrelevant responses are negligible in this condition (TD: $1.4 \%$, $S D=4.9 \%$; HFA: $3.7 \%, S D=7.1 \%$; SLI: $1.9 \%, S D=5.3 \%$ ), as are the incorrect 


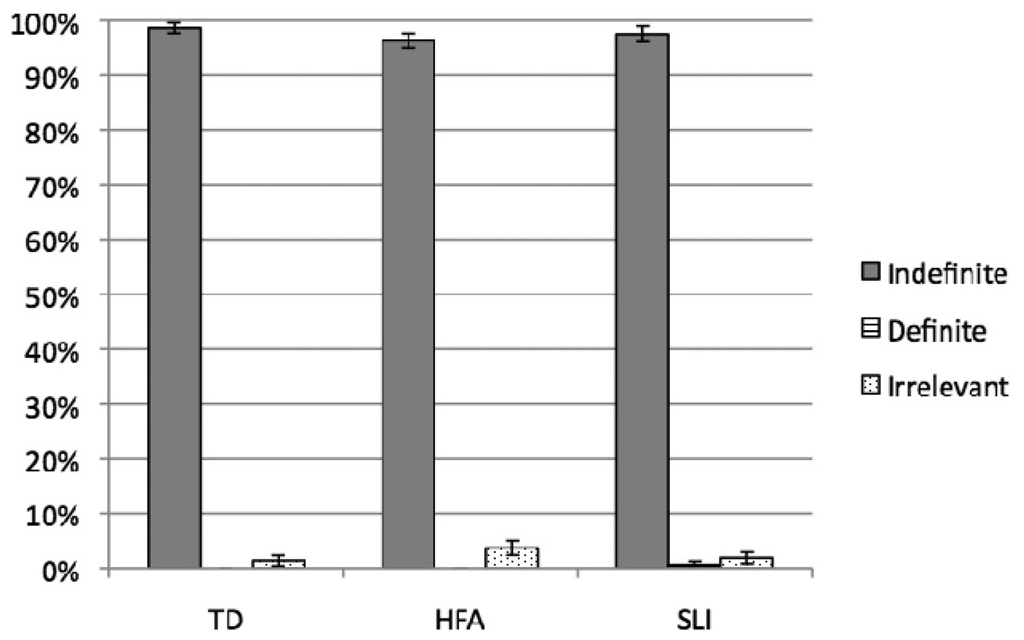

Figure 2. Indefinite referential condition proportions of indefinite (correct), definite (incorrect), and irrelevant responses.

definite responses (TD: 0\%; HFA: 0\%; SLI: 0.6\%, SD =3.2\%). Kruskal-Wallis test results reveal no significant differences between the groups on indefinites, $\chi^{2}(2)=2.381, p=.304$, definites, $\chi^{2}(2)=2.000, p=.368$, or irrelevant responses, $\chi^{2}(2)=2.495, p=.287$. In other words, none of the child groups differ significantly from one another in their performance on the indefinite referential or indefinite nonreferential conditions.

In contrast, definite articles are not always chosen in the definite condition, as illustrated in Figure 3. Whereas the TD children produce a high percentage of correct definite articles in the definite condition (TD: $95.1 \%, S D=12.1 \%$ ), the proportions of the HFA and the SLI groups' correct definite responses are substantially lower (HFA: $80.3 \%, S D=26.6 \%$; SLI: $80.9 \%, S D=24.8 \%$ ). Parallel to this, the TD children show low proportions of incorrect indefinite responses $(3.7 \%$, $S D=10.7)$, while the HFA and SLI groups give incorrect indefinite responses at rates of $15.4 \%(\mathrm{HFA}: S D=22.1 \%)$ and $13 \%(\mathrm{SLI}: S D=19.8 \%)$. As for irrelevant responses, all groups show some, but the percentages are low (HFA: $4.3 \%, S D$ $=8.8 \%$; SLI, $6.8 \%, S D=15.5 \%$ ). A Kruskal-Wallis test reveals a significant difference between the proportions of correct definite responses of the TD, HFA, and SLI groups, $\chi^{2}(2)=8.676, p<.05$. Mann-Whitney $U$ tests between the different pairs of groups show that the difference between the HFA and the TD group is significant $(U=245, p<.05)$. The same holds for the SLI and the TD group ( $U=224.5, p \leq .005)$. The HFA and SLI groups do not differ significantly from one another $(U=356, p=.875)$. The lower use of correct definite articles in the definite condition by the HFA group and the SLI group is largely due to the substitution of indefinite articles. Both the HFA and the SLI groups' indefinite article proportions are significantly higher than that of the TD children (HFA: $U=$ $272, p<.017$, SLI: $U=265.5, p<.05)$. A smaller part of the definite condition 


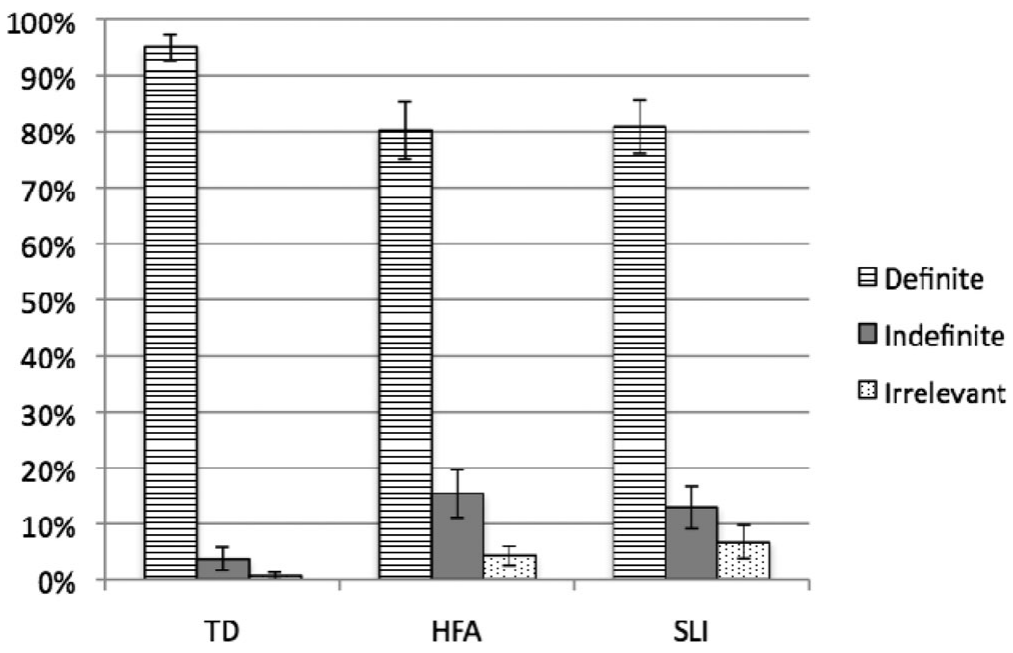

Figure 3. Definite condition: proportions of definite (correct), indefinite (incorrect), and irrelevant responses.

errors consists of irrelevant responses, including demonstratives (Hij zit te knuffelen met die hond. "He is cuddling with that dog.") and some article omissions (Hij knuffelde _ knuffelbeer. "He cuddled _ teddybear"): 7\% for the SLI group, 4\% for the HFA group, and $4 \%$ for the TD children. However, we find no evidence for significant differences in the production of irrelevant answers between child groups, $\chi^{2}(2)=2.931, p=.231$.

\section{ToM}

Keeping in mind that the choice of a referential indefinite article may be related to ToM, we present the results on the false belief items of the nonverbal ToM task as also reported in Schaeffer (2016).

Figure 4 shows that all groups perform equally on this task, of which the maximal score was 3: no significant difference was found: (HFA: 2.3 correct, $S D=0.67$; TD: 1.9 correct, $S D=0.72$; and SLI: 2.1 correct, $S D=0.82$ ); Kruskal-Wallis: $\left.\chi^{2}(2)=5.130, p=.08\right)$. All groups perform significantly above chance level as indicated by one-sample $t$ tests performed for each group: HFA, $t(26)=4.128$, $p<.001$; TD, $t(26)=6.211, p<.001 ;$ and SLI, $t(26)=2.558, p=.017$.

\section{Memory}

The results of the digit span forward, digit span backward, and the odd-one-out are given in Figure 5. Because of its different scoring measure (percentages), the results of the NWR task are presented separately in Figure 6. Recall our hypothesis that weak memory skills may cause overgeneration of the indefinite article in the definite condition of the article choice test. 


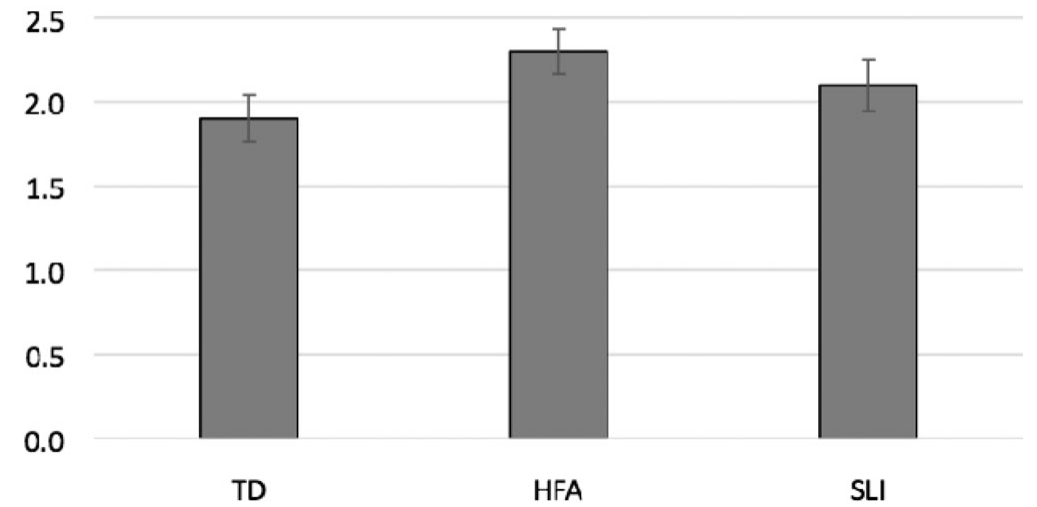

Figure 4. Number of items correct ( \pm 1 standard error of the mean) on false belief items of the nonverbal theory of mind task (maximal score $=3$ ).

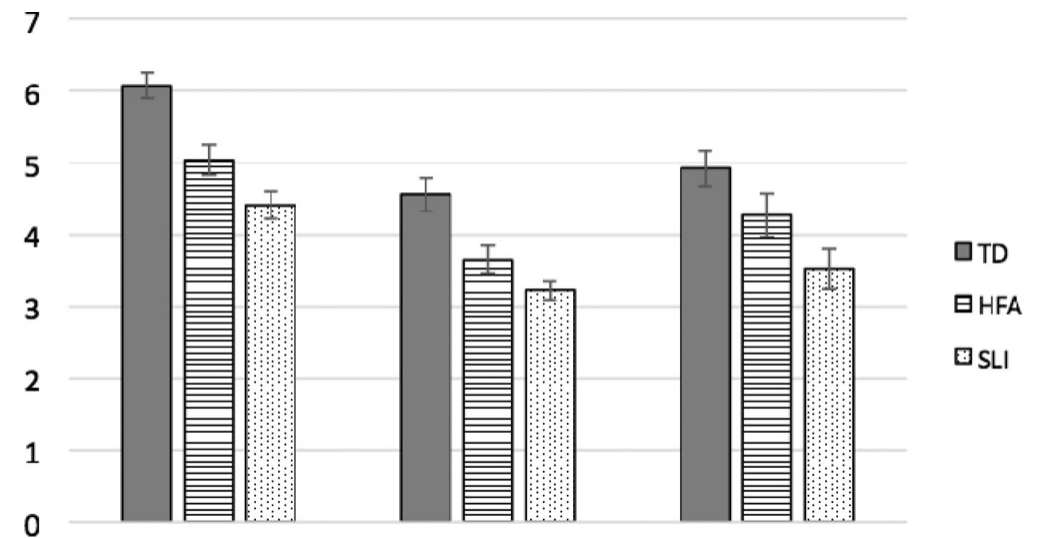

\section{Digit Span Forward Digit Span Backward Odd-One-Out}

Figure 5. Results ( \pm 1 standard error of the mean) on the digit span forward, digit span backward (average maximum number of digits repeated correctly), and odd-one-out tasks (memory level, maximum $=6$ ).

The NWR task, taken as a measure of phonological memory, reveals a significant effect of group, $\chi^{2}(2)=50.382, p<.001$. The TD children significantly outperform both the SLI group $(U=12, p<.001)$ and the HFA group $(U=218.5$, $p \leq .05)$. In addition, the children with HFA score significantly higher than the children with SLI $(U=27, p<.001)$.

The results of our second measure for phonological memory, the digit span forward task (Figure 5), confirm this pattern of results. The overall group effect is 


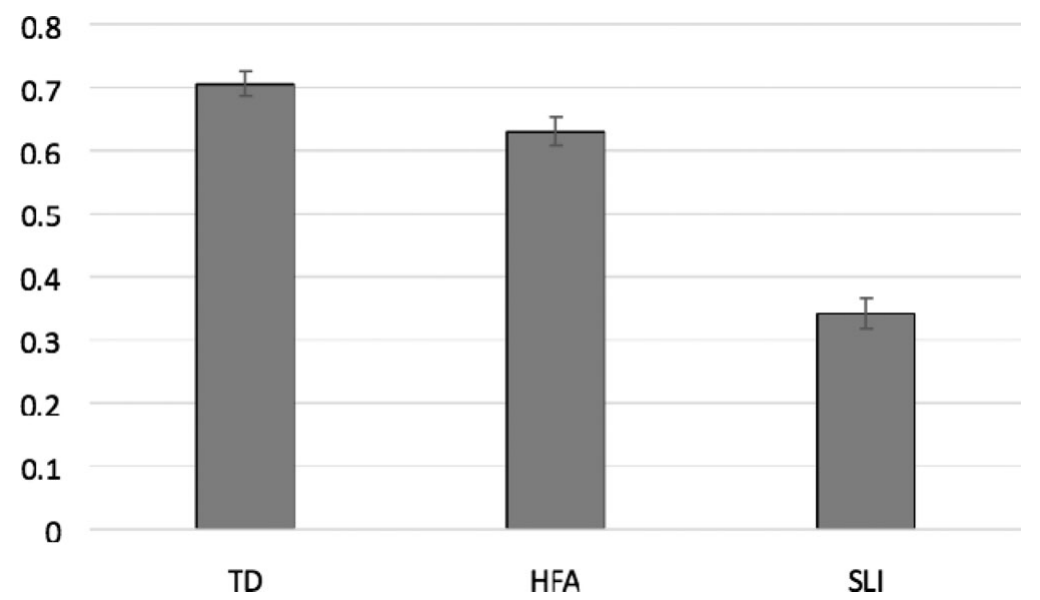

Figure 6. Results ( \pm 1 standard error of the mean) on the nonword repetition task (percentage correct out of 40 items).

significant, $\chi^{2}(2)=26.750, p<.001$, and the TD children significantly outperform both clinical groups (SLI: $U=86, p<.001$, HFA: $U=169.5, p \leq .001$ ). Moreover, the HFA group performs significantly better than the SLI group $(U=242.5$, $p<.05)$.

With regard to verbal working memory, the digit span backward task shows a slightly different pattern (Figure 5). A Kruskal-Wallis test reveals a significant difference in performance between the child groups, $\chi^{2}(2)=18.952, p<.001$. Further testing indicates that both the children with HFA $(U=201.5, p<.05)$ and the children with SLI $(U=132.5, p \leq .001)$ perform significantly more poorly than their TD age mates. However, no significant difference is found between the performance of the two clinical groups $(U=268.5, p=.11)$.

Finally, as for nonverbal working memory, the results presented in Figure 5 on the odd-one-out task suggest a pattern similar to the other memory tasks. However, when the significant effect of group, $\chi^{2}(2)=11.087, p<.01$, is investigated more closely, we find that, in contrast to the phonological and verbal working memory tasks, there is no evidence that the children with HFA differ from their TD peers $(U=256, p=.12)$. The children with SLI do significantly differ from the TD group $(U=170.5, p \leq .001)$, but not from the HFA group $(U=251, p=.07)$.

\section{Summary group results}

The group results are summarized in Table 3 .

\section{Correlations}

Table 3 shows that the areas in which the HFA group as well as the SLI group score significantly lower than the TD group are (a) definite contexts; (b) phonological 
Schaeffer et al.: Article choice in children with HFA and with SLI

Table 3. Group results of HFA and SLI groups compared to TD group

\begin{tabular}{|c|c|c|}
\hline & HFA & SLI \\
\hline AC: indefinite ref. contexts & TD-like & TD-like \\
\hline False belief & TD-like & TD-like \\
\hline AC: definite contexts & $\begin{array}{l}\text { Overgeneration of indefinite } \\
\text { article }\end{array}$ & $\begin{array}{l}\text { Overgeneration of indefinite } \\
\text { article }\end{array}$ \\
\hline ToM & TD-like & TD-like \\
\hline Phonological memory & Poorer than TD age mates & Poorer than TD age mates \\
\hline Verbal WM & Poorer than TD age mates & Poorer than TD age mates \\
\hline Nonverbal WM & TD-like & Poorer than TD age mates \\
\hline
\end{tabular}

Note: HFA, high-functioning autism; SLI, specific language impairment; TD, typically developing; AC, article choice; ToM, theory of mind; WM, working memory.

memory (but note that the children with HFA perform better than the children with SLI); and (c) verbal working memory. In contrast, both clinical groups perform TD-like on false belief and the two indefinite conditions of the article choice experiment. To investigate potential associations between the different task scores we performed Spearman rank correlation orders between the ToM and memory tasks on the one hand and the different conditions of the article choice on the other hand. The only significant correlation found is between the definite condition of the article choice task and NWR. Across groups, the score on the NWR task was positively correlated with the accuracy on the definite condition $(\rho=.232, p<.05)$. All other correlations were nonsignificant, including correlations within (HFA and SLI) groups.

\section{DISCUSSION}

In our twofold research question we asked (a) whether clinical child populations such as HFA and SLI would have problems with article choice, and (b) if so, whether such non-TD-like performance on article choice would be due to underdeveloped false belief skills or weak phonological and/or working memory. Neither the children with HFA nor the children with SLI older than 5 overgenerated definite articles in indefinite referential contexts, as younger TD children do cross-linguistically. This result was predicted for the SLI group, but not for the HFA group. Recall that overgeneration of the definite article in TD children was explained by the pragmatic CNSA, stating that speaker and hearer assumptions are always independent, reminding of ToM. Although the predicted correlation between the false belief scores and the scores on the indefinite referential condition of the article choice task was not significant, the fact that none of the children with HFA or SLI overgenerated the definite article in this condition is in line with the result that both clinical groups performed TD-like on the false belief items of the ToM task. ${ }^{2}$ This suggests that even the children with HFA have no particular problems separating hearer from speaker assumptions, which is not what we predicted, based on findings in previous literature that children with HFA suffer from underdeveloped ToM (Baron-Cohen, 1988; Colle et al., 2007; Durrleman et al., 
2016; Sperber \& Wilson, 2002). The fact that all our groups, including the children with HFA, scored above chance on the ToM task indicates that there are children with HFA who do have false belief skills.

Nevertheless, the children with HFA and SLI we tested demonstrated a different type of problem with article choice, namely, overgeneration of the indefinite article in definite contexts. Thus, despite the fact that the children with HFA and the children with SLI we tested have different profiles in terms of grammar (CELF4-NL) and social communication skills (CCC-2-NL), they performed similarly on article choice. Moreover, both clinical groups performed significantly more poorly than the TD children on phonological memory (NWR and digit span forward) and verbal working memory (digit span backward). This was predicted for the SLI group. Even though the children with HFA performed significantly more poorly on all verbal memory tasks than the TD children, they scored significantly higher than the children with SLI on both phonological memory tasks (NWR and digit span forward), indicating that the phonological working memory of the children with HFA is less impaired than that of the children with SLI. Furthermore, the children with SLI also scored poorly on the nonverbal working memory task (oddone-out), as predicted, whereas the HFA group performed TD-like on this test. Note, however, that the HFA group did not perform significantly better than the SLI group on the nonverbal working memory task (although the $p$ value of .07 indicates near significance). These results suggest an association between phonological and working memory on the one hand and production of definite articles on the other hand. We expected this for the SLI group, based on Polite et al.'s (2011) findings and proposed account, but our results suggest that this may apply to the children with HFA as well. Closer scrutiny of this potential association by the calculation of Spearman rank correlation orders revealed a significant correlation between overgeneration of the indefinite article and NWR, but not with any of the other memory tests. This suggests a relationship between article choice in definite contexts and phonological memory. Inspired by the hypothesis that overly liberal interpretation/overgeneration of the indefinite article in TD Dutch child language (Keydeniers et al., 2017; van Hout et al., 2010) is due to the failure to draw the scalar implicature related to definiteness, and by Polite et al.'s (2011) suggestion that in the children with SLI overgeneration of the indefinite article may be caused by weak working memory, we propose the following account.

Recall that articles have a logical/semantic (truth-conditional) meaning and a pragmatic meaning. The use of the indefinite article $a$ is always logically/ semantically correct, even in definite contexts: a sentence such as She rolled a ball in the definite context exemplified in (9) is still logically true. In this sense, the indefinite article can be considered the default article. However, in addition to evaluating the truth value, article use requires the consideration of the definiteness scale ( $<a$, the $>$ ), in which $a$ is the weaker and the is the stronger member in terms of informativeness (Hawkins, 1991; Horn, 2006). Subsequently, a choice must be made between the two. This choice requires determining the appropriate degree of informativeness for the given context. If the strongest degree of informativeness is required (referent is assumed to exist by speaker and hearer, i.e., in the common ground), the stronger member the is chosen. If weaker informativeness is required, the weak member $a$ should be chosen. Choosing the weak member $a$ 
on the basis of the definiteness scale renders a scalar implicature: as the maxim of quantity requires to be as informative as necessary, but no more, the choice of the indefinite article implicates that the definite article is too informative. Now, it is crucial that, during this evaluation process (choosing between the indefinite and the definite article), the preceding discourse must be stored in phonological memory, to be integrated with the definiteness scale. If this phonological memory is weak, underdeveloped, or impaired, as seems to be the case in our HFA and SLI child populations, the preceding discourse may be lost, making it impossible to compare the degrees of informativeness of the two members of the definiteness scale with respect to the context, and thus to calculate a scalar implicature. We propose that this is exactly what is happening in the HFA and SLI child groups we tested: because of their weak phonological memory, as attested by their low NWR scores (and, to a lesser degree, by their low digit span forward scores), they sometimes lose the relevant information of the preceding discourse during the process of choosing the correct article. This prevents the calculation of a scalar implicature, resulting in the default use of the indefinite article, which, even in definite contexts, is logically/semantically correct (but pragmatically infelicitous). In indefinite contexts, the noncalculation of the scalar implicature resulting in the use of the default indefinite article does not yield a visible error, as the target article is indefinite. As such, our account is an elaboration of Polite et al.'s (2011) suggestion, and makes it more precise: "losing track of discourse," as Polite et al. call it, means preventing the calculation of the scalar implicature that arises from integrating the preceding discourse with the definiteness scale. If the preceding discourse cannot be accessed, integration does not take place, and a scalar implicature is not calculated.

Of course, the proposed account is a hypothesis that needs further investigation. It is important to realize that, although the correlation between scores on the NWR and the definite condition of the article choice task was significant across groups, the HFA group's NWR scores were significantly higher than those of the SLI group, whereas the HFA and SLI definite condition scores did not differ. This may indicate that the relatively weak phonological memory of the children with HFA is not the only factor contributing to the overgeneration of the indefinite article in the HFA group. Future research should test different types of scalar implicatures (including nonverbal ones) independently in HFA and SLI, alongside different types of phonological memory and verbal working memory, and of course article choice. Moreover, in order to obtain more statistical power, larger groups should be tested. This may provide more insight in which types of memory are correlated with the skills of adequately considering scales and drawing scalar implicatures. Although we did not find a significant correlation between the overgeneration of indefinite articles and verbal working memory, the verbal working memory scores of both the HFA and the SLI group were significantly lower than those of the TD children. It is feasible that weak verbal working memory is also related to overgeneration of the indefinite article: drawing a scalar implicature implies manipulation of the definiteness scale, which is likely to be executed in verbal working memory.

In conclusion, despite the differences between children with HFA and SLI in terms of grammar (CELF-4-NL) and social communication (CCC-2-NL), both 
clinical groups seem to suffer from phonological memory and verbal working memory problems. Impaired phonological memory and verbal working memory are likely to prevent the calculation of the scalar implicature related to definiteness, resulting in the production of indefinite articles in definite contexts.

\section{APPENDIX A}

\section{Sample scenario indefinite referential condition}

Situation: Picture of Dora who has drawn a heart (visible to participant, but not to experimenter).

Exp: Hey, who do you see in the picture?

Participant: Dora!

Exp: And what did Dora just do?

Target: She drew a heart.

\section{Sample scenario indefinite nonreferential condition}

Situation: Picture of Big Bird thinking with a pencil in his hand (visible to participant, but not to experimenter).

Exp: Hey, who do you see in the picture?

Participant: Big Bird!

Exp 2: Big Bird says: “Oh, I am so bored, I don’t know what to do. Oh, you know what? I'll go to the forest and draw something!"

Exp: What do you think Big Bird is going to do in the forest?

Target: He is going to draw a tree.

\section{ACKNOWLEDGMENTS}

This project was made financially possible by the Priority Area Amsterdam Brain \& Cognition, University of Amsterdam. Data on SLI was collected in collaboration with Iris Duinmeijer and our research assistants: Jorik Geutjes, Doatske de Haan, Leanne Matimba, Irene Rademaker, Kim Schoof, and Sybren Spit. We are grateful to all the schools, children, teachers, and parents who participated in this study.

\section{NOTES}

1. The data set used in the present study is the same as in Schaeffer (2016), who explores the question as to whether children with SLI and children with HFA are on the same continuum, with a large test battery, including a test of article choice. The current study, of which an earlier and different version was presented at BUCLD 2014, zooms in on article choice, adds verbal working memory and phonological memory results, and provides an analysis of the article choice errors.

2. Recall, however, that the $p$ value was .08 , suggesting that with larger statistical power we may find significant differences between the groups. Nevertheless, such a difference would go into a surprising direction, with the HFA group scoring highest on the ToM task, and the TD group scoring lowest. We therefore believe that this ToM task should be replicated to confirm the validity of our results. 
Schaeffer et al.: Article choice in children with HFA and with SLI

\section{REFERENCES}

Abbott, B. (1999). Support for a unique theory of definiteness. In T. Matthews \& D. Strolovitch (Eds.), Proceedings from Semantics and Linguistic Theory 9 (SALT) 9, pp. 1-15. Ithaca, NY: CLC Publications.

Abbott, B. (2003). A reply to Szabó's "Descriptions and uniqueness." Philosophical Studies, 113, 223-231.

Archibald, L. M., \& Gathercole, S. E. (2006). Short-term and working memory in specific language impairment. International Journal of Language \& Communication Disorders, 41, 675-693.

Baddeley, A. D. (1986). Working memory. Oxford: Clarendon Press.

Baddeley, A. (2003). Working memory: Looking back and looking forward. Nature Reviews Neuroscience, 4, 829-839.

Baddeley, A. D., \& Hitch, G. (1974). Working memory. Psychology of Learning and Motivation, 8, 47-89.

Baron-Cohen, S. (1988). Social and pragmatic deficits in autism: Cognitive or affective? Journal of Autism and Developmental Disorders, 18, 379-402.

Bennetto, L., Pennington, B. F., \& Rogers, S. J. (1996). Intact and impaired memory functions in autism. Child Development, 67, 1816-1835.

Bishop, D. V. M. (2000). Pragmatic language impairment: A correlate of SLI, a distinct subgroup, or part of the autistic continuum. In D. V. M. Bishop \& L. V. Leonard (Eds.), Speech and language impairments in children: Causes, characteristics, intervention and outcome (pp. 99-113). East Sussex: Psychology Press.

Bishop, D. V. M., Chan, J., Adams, C., Hartley, J., \& Weir, F. (2000). Conversational responsiveness in specific language impairment: Evidence of disproportionate pragmatic difficulties in a subset of children. Development and Psychopathology, 12, 177-199.

Bishop, D. V., North, T., \& Donlan, C. H. R. I. S. (1996). Nonword repetition as a behavioural marker for inherited language impairment: Evidence from a twin study. Journal of Child Psychology and Psychiatry, 37, 391-403.

Botting, N., \& Conti-Ramsden, G. (2003). Autism, primary pragmatic difficulties, and specific language impairment: Can we distinguish them using psycholinguistic markers? Developmental Medicine \& Child Neurology, 45, 515-524.

Call, J., \& Tomasello, M. (1999). A nonverbal false belief task: The performance of children and great apes. Child Development, 70, 381-395.

Carston, R. (1998). Informativeness, relevance and scalar implicature. In R. Carston \& S. Uschida (Eds.), Relevance theory: Applications and implications (pp. 79-236). Amsterdam: John Benjamins.

Chierchia, G. (2004). Scalar implicatures, polarity phenomena, and the syntax/pragmatics interface. Structures and Beyond, 3, 39-103.

Chondrogianni, V., \& Marinis, T. (2015). Production of definite and indefinite articles in typically developing English-speaking children and children with SLI. Lingua, 155, 9-28.

Colle, L., Baron-Cohen, S., \& Hill, J. (2007). Do children with autism have a theory of mind? A nonverbal test of autism vs. specific language impairment. Journal of Autism and Developmental Disorders, 37, 716-723.

De Cat, C. (2011). Information tracking and encoding in early L1: Linguistic competence vs. cognitive limitations. Journal of Child Language, 38, 828-860.

Dollaghan, C., \& Campbell, T. F. (1998). Nonword repetition and child language impairment. Journal of Speech, Language, and Hearing Research, 41, 1136-1146.

Durrleman, S., Burnel, M., Thommen, E., Foudon, N., Sonié, S., Reboul, A., \& Fourneret, P. (2016). The language cognition interface in ASD: Complement sentences and false belief reasoning. Research in Autism Spectrum Disorders, 21, 109-120.

Eigsti, I. M., de Marchena, A. B., Schuh, J. M., \& Kelley, E. (2011). Language acquisition in autism spectrum disorders: A developmental review. Research in Autism Spectrum Disorders, 5, 681691. 
Schaeffer et al.: Article choice in children with HFA and with SLI

Friedmann, N., \& Novogrodsky, R. (2008). Subtypes of SLI: SySLI, PhoSLI, LeSLI, and PraSLI. In A. Gavarró \& M. J. Freitas (Eds.), Language acquisition and development (pp. 205-217). Newcastle: Cambridge Scholars Press.

Friedmann, N., \& Novogrodsky, R. (2011). Which questions are most difficult to understand? The comprehension of Wh questions in three subtypes of SLI. Lingua, 121, 367-382.

Frith, U. (1989). Autism: Explaining the enigma. British Journal of Developmental Psychology, 3, $465-468$.

Gathercole, S. E. (2006). Nonword repetition and word learning: The nature of the relationship. Applied Psycholinguistics, 27, 513-543.

Gathercole, S. E., \& Baddeley, A. D. (1990). Phonological memory deficits in language disordered children: Is there a causal connection? Journal of Memory and Language, 29, 336360.

Gathercole, S. E., Willis, C. S., Baddeley, A. D., \& Emslie, H. (1994). The children's test of nonword repetition: A test of phonological working memory. Memory, 2, 103-127.

Geurts, H. M. (2007). Handleiding Nederlandse Children's Communicaton Checklist (2nd ed.). Lisse, The Netherlands: Swets \& Zeitlinger.

Girbau, D., \& Schwartz, R. G. (2007). Non-word repetition in Spanish-speaking children with Specific Language Impairment (SLI). International Journal of Language \& Communication Disorders, 42, 59-75.

Gordishevsky, G., \& Avrutin, S. (2004). Optional omissions in an optionally null subject language. In J. van Kampen \& S. Baauw (Eds.), Proceedings of GALA 2003 (Vol. 1, pp. 187-198). LOT Occasional series 3. Utrecht: Utrecht University Press.

Grice, H. P. (1975). Logic and conversation. In P. Cole \& J. Morgan (Eds.), Syntax and semantics 3: Speech acts (pp. 41-58). New York: Academic Press.

Griffith, E. M., Pennington, B. F., Wehner, E. A., \& Rogers, S. J. (1999). Executive functions in young children with autism. Child Development, 70, 817-832.

Hawkins, J. A. (1991). On (in)definite articles: Implicatures and (un)grammaticality prediction. Journal of Linguistics, 27, 405-442.

Heim, I. (1982). The semantics of definite and indefinite NPs (Doctoral dissertation, University of Massachusetts, Amherst).

Henry, L. A. (2001). How does the severity of a learning disability affect working memory performance? Memory, 9, 233-247.

Henry, L. A., Messer, D. J., \& Nash, G. (2012). Executive functioning in children with specific language impairment. Journal of Child Psychology and Psychiatry, 53, 37-45.

Horn, L. R. (1989). A natural history of negation. Chicago: University of Chicago Press.

Horn, L. R. (2006). Toward a Fregean pragmatics: Voraussetzung, Nebengedanke, Andeutung. In L. R. Horn \& I. Kecskes (Eds.), Explorations in pragmatics: Linguistic, cognitive, and intercultural aspects (pp. 39-69). Berlin: Mouton.

Janssen, B. E. (2016). The acquisition of gender and case in Polish and Russian: A study of monolingual and bilingual children (Doctoral dissertation, University of Amsterdam).

Joseph, R. M., Steele, S. D., Meyer, E., \& Tager-Flusberg, H. (2005). Self-ordered pointing in children with autism: Failure to use verbal mediation in the service of working memory? Neuropsychologia, 43, 1400-1411.

Karmiloff-Smith, A. (1979). A functional approach to child language. Cambridge: Cambridge University Press.

Keydeniers, D. J., Eliazer, J., \& Schaeffer, J. C. (2017). Definite-indefinite article choice in Dutch child language. Manuscript in preparation.

Kort, W., Schittekatte, M., \& Compaan, E. (2008). CELF-4-NL: Clinical Evaluation of Language Fundamentals-Vierde-Editie. Amsterdam: Pearson Assessment and Information.

Koshino, H., Carpenter, P. A., Minshew, N. J., Cherkassky, V. L., Keller, T. A., \& Just, M. A. (2005). Functional connectivity in an fMRI working memory task in high-functioning autism. NeuroImage, 24, 810-821. 
Schaeffer et al.: Article choice in children with HFA and with SLI

Krämer, I. (2003). Reference of indefinite and pronominal noun phrases in a story context: English children's comprehension. In B. Beachley, A. Brown, \& F. Conlin (Eds.), Proceedings of the 27th Boston University Conference on Language Development (pp. 449-460). Somerville, MA: Cascadilla Press.

Levinson, S. (2000). Presumptive meanings: The theory of generalized conversational implicature. Cambridge, MA: MIT Press.

Levy, F. (2007). Theories of autism. Australian and New Zealand Journal of Psychiatry, 41, 859-868.

Luna, B., Minshew, N. J., Garver, K. E., Lazar, N. A., Thulborn, K. R., Eddy, W. F., \& Sweeney, J. A. (2002). Neocortical system abnormalities in autism: An fMRI study of spatial working memory. Neurology, 59, 834-840.

Maratsos, M. P. (1976). The use of definite and indefinite reference in young children: An experimental study of semantic acquisition. Cambridge: Cambridge University Press.

Miller, C. A. (2001). False belief understanding in children with specific language impairment. Journal of Communication Disorders, 34, 73-86.

Montgomery, J. W. (2003). Working memory and comprehension in children with specific language impairment: What we know so far. Journal of Communication Disorders, 36, 221-231.

Ozonoff, S., \& Strayer, D. L. (2001). Further evidence of intact working memory in autism. Journal of Autism and Developmental Disorders, 31, 257-263.

Perovic, A., Modyanova, N., \& Wexler, K. (2013a). Comprehension of reflexive and personal pronouns in children with autism: A syntactic or pragmatic deficit? Applied Psycholinguistics, 34, 813835.

Perovic, A., Modyanova, N., \& Wexler, K. (2013b). Comparison of grammar in neurodevelopmental disorders: The case of binding in Williams syndrome and autism with and without language impairment. Language Acquisition, 2, 133-154.

Polite, E. J., Leonard, L. B., \& Roberts, F. D. (2011). The use of definite and indefinite articles by children with specific language impairment. International Journal of Speech-Language Pathology, 13, 291-300.

Pouscoulous, N., Noveck, I. A., Politzer, G., \& Bastide, A. (2007). A developmental investigation of processing costs in implicature production. Language Acquisition, 14, 347-375.

Premack, D., \& Woodruff, G. (1978). Does the chimpanzee have a theory of mind? Behavioral and Brain Sciences, 1, 515-526.

Rispens, J., \& Baker, A. (2012). Nonword repetition: The relative contributions of phonological shortterm memory and phonological representations in children with language and reading impairment. Journal of Speech, Language, and Hearing Research, 55, 683-694.

Russell, B. (1905). On denoting. Mind, 14, 479-493.

Russell, J., Jarrold, C., \& Henry, L. (1996). Working memory in children with autism and with moderate learning difficulties. Journal of Child Psychology and Psychiatry, 37, 673-686.

Schaeffer, J. (2016). Linguistic and cognitive abilities in children with specific language impairment as compared to children with high-functioning autism. Language Acquisition, 1-19. doi: 10.1080/10489223.2016.1188928

Schaeffer, J., Hacohen, A., \& Bernstein, A. (2003). On the acquisition of DP in English-speaking children with SLI. In B. Beachley, A. Brown, \& F. Colin (Eds.), Proceedings of the 27th Boston University Conference on Language Development (pp. 716-726). Somerville, MA: Cascadilla Press.

Schaeffer, J., \& Matthewson, L. (2005). Grammar and pragmatics in the acquisition of article systems. Natural Language \& Linguistic Theory, 23, 53-101.

Schafer, R., \& de Villiers, J. (2000). Imagining articles: What $a$ and the can tell us about the emergence of DP. In M. LaMendola \& J. Scott (Eds.), Proceedings of the 24th annual Boston University conference on language development (Vol. 2, pp. 609-620). Somerville, MA: Cascadilla Press.

Schuh, J. M., \& Eigsti, I. M. (2012). Working memory, language skills, and autism symptomatology. Behavioral Sciences, 2, 207-218. 
Schaeffer et al.: Article choice in children with HFA and with SLI

Sperber, D., \& Wilson, D. (2002). Pragmatics, modularity and mind-reading. Mind and Language, 17, 3-23.

Stalnaker, R. (1974). Pragmatic presuppositions. In M. K. Munitz \& P. Unger (Eds.), Semantics and philosophy (pp. 197-214). New York: New York University Press.

Stalnaker, R. (1978). Assertion. In P. Cole (Ed.), Syntax and semantics: Vol. 9. Pragmatics (pp. 313332). New York: Academic Press.

Tager-Flusberg, H. (1989). A psycholinguistic perspective on language development in the autistic child. In G. Dawson (Ed.), Autism: Nature, diagnosis, and treatment (pp. 92-115). New York: Guilford Press.

van der Lely, H. K. (1998). SLI in children: Movement, economy, and deficits in the computationalsyntactic system. Language Acquisition, 7, 161-192.

van Hout, A., Harrigan, K., \& de Villiers, J. (2010). Asymmetries in the acquisition of definite and indefinite NPs. Lingua, 120, 1973-1990.

Verhagen, J., \& Leseman, P. (2016). How do verbal short-term memory and working memory relate to the acquisition of vocabulary and grammar? A comparison between first and second language learners. Journal of Experimental Child Psychology, 141, 65-82.

Vugs, B., Cuperus, J., Hendriks, M., \& Verhoeven, L. (2013). Visuospatial working memory in specific language impairment: A meta-analysis. Research in Developmental Disabilities, 34, 25862597.

Wechsler, D. (1974). Wechsler Intelligence Scale for Children-Revised. New York: Psychological Corporation.

Weismer, S. E., Evans, J., \& Hesketh, L. J. (1999). An examination of verbal working memory capacity in children with specific language impairment. Journal of Speech, Language, and Hearing Research, 42, 1249-1260.

Weismer, S. E., Tomblin, J. B., Zhang, X., Buckwalter, P., Chynoweth, J. G., \& Jones, M. (2000). Nonword repetition performance in school-age children with and without language impairment. Journal of Speech, Language, and Hearing Research, 43, 865-878.

Wellman, H. M., Cross, D., \& Watson, J. (2001). Meta-analysis of theory-of-mind development: The truth about false belief. Child Development, 72, 655-684.

Westergaard, M. R. (2008). Verb movement and subject placement in the acquisition of word order: Pragmatics or structural economy? In P. Guijarro-Fuentes, M. P. Larranaga, \& J. Clibbens (Eds.), First language acquisition of morphology and syntax (pp. 61-86). Amsterdam: John Benjamins.

Wilson, D., \& Sperber, D. (2004). Experimental pragmatics. In F. Jackson \& M. Smith (Eds.), Handbook of contemporary analytical philosophy (pp. 607-632). Oxford: Blackwell.

Wimmer, H., \& Perner, J. (1983). Beliefs about beliefs: Representation and constraining function of wrong beliefs in young children's understanding of deception. Cognition, 13, 103-128.

Zehler, A. M., \& Brewer, W. F. (1982). Sequence and principles in article system use: An examination of $A$, The, and Null acquisition. Child Development, 53, 1268-1274. 